\title{
Philosophiques
}

\section{Le pays de la culture}

\section{Fernand Couturier}

Volume 5, numéro 1, avril 1978

URI : https://id.erudit.org/iderudit/203095ar

DOI : https://doi.org/10.7202/203095ar

Aller au sommaire du numéro

Éditeur(s)

Société de philosophie du Québec

ISSN

0316-2923 (imprimé)

1492-1391 (numérique)

Découvrir la revue

Citer ce document

Couturier, F. (1978). 2. Le pays de la culture. Philosophiques, 5(1), 195-199.

https://doi.org/10.7202/203095ar

Ce document est protégé par la loi sur le droit d'auteur. L'utilisation des services d'Érudit (y compris la reproduction) est assujettie à sa politique d'utilisation que vous pouvez consulter en ligne.

https://apropos.erudit.org/fr/usagers/politique-dutilisation/
Cet article est diffusé et préservé par Érudit.

Érudit est un consortium interuniversitaire sans but lucratif composé de l'Université de Montréal, l'Université Laval et l'Université du Québec à Montréal. Il a pour mission la promotion et la valorisation de la recherche. https://www.erudit.org/fr/ 


\title{
2. LE PAYS DE LA CULTURE
}

\author{
par Fernand Couturier
}

"Dépayser la culture " était le titre de l'article de Michel Morin et de Claude Bertrand, paru le 15 et le 22 octobre 1977 dans le cahier "Culture et Société " du journal Le Devoir.

Il faut savoir gré aux auteurs de refuser la nationalisme en culture. Un certain amour et une certaine recherche de la québécitude prennent facilement l'allure d'un mouvement de repli sur soi, et il y a de ces retours à l'origine qui se présentent moins comme ressourcement régénérateur que comme "fixation identitaire" dont les odeurs de renfermé sont déjà perceptibles au sens olfactif de la moyenne. Mais faut-il pour éliminer et éviter ce nationalisme " dépayser la culture" ? Il se pourrait alors qu'on fasse déboucher la culture sur une espèce d'apatridie sans nom et qu'on la confine dans une désertique irréalité. C'est l'impression qui se dégage nettement de l'article. Regardons.

D'abord on y parle de l'identité d'une manière assez négative en empruntant à la langue de la psychologie psychanalysante : l'identité, c'est la fixation identitaire et la manifestation de cette identité, c'est l'autoreprésentation narcissique. Et quand on essaye de caractériser plus positivement ce qu'est l'identité de l'individu, on la présente, utilisant le même recours, comme un écartèlement intérieur déchirant et angoissant défini comme une aliénation.

Le temps ne serait-il pas venu de mettre de côté, ne serait-ce que provisoirement, en raison de ses références psychologique et sociologique à la morbidité et à l'esclavage, ce terme d'aliénation, quand on veut parler de cette exigence fondamentale de l'humain de se dépasser toujours sans pour autant cesser d'être lui-même? Il semble que la pensée éviterait de la sorte de mauvaises orientations et trouverait plus de disponibilité pour la question vitale de l'ouverture à tout ce qui est autre. L'ouverture à l'autre n'a de sens que 
comme accueil de l'autre, et les deux, qui ne font qu'un en réalité, supposent un soi bien établi dans sa distinction et reconnaissable comme tel tout au long du processus de dépassement. La nécessité du dépassement, qui est marche vers l'autre et accueil de l'autre, ne doit pas être réduite à la fatalité d'une pure fugitivité ou à une évanescence absolue qui ne serait que pure trace, c'est-à-dire trace de rien. En clair, l'individu qui se dépasse demeure en tant que cet individu.

De plus, il apparaît tout à fait vain, comme il est justement souligné dans l'article, de restaurer l'origine, de forcer ou d'importuner la réalité par le passé. Car le passé est du révolu, et l'installer dans le présent ne paraît pas avoir plus de sens que d'élire domicile chez lui. Seulement, peut-on légitimement se limiter à concevoir ainsi le passé ? On est plus près du phénomène de l'histoire si, au lieu de voir le passé comme un point de départ dont on peut se départir, on l'expérimente comme l'ouverture d'un possible dans lequel on demeure, agit et vit, tout comme c'est dans le présent et à partir de lui que s'ouvre l'avenir dans lequel on pourra également vivre. Le devenir historique apparaît comme une exploitation ou, mieux, une explicitation des possibilités humaines d'exister et, en tant que tel, implique à la fois les trois moments du temps. On doit malheureusement à le mentalité historiciste la manie de considérer abstraitement le passé comme séparé ou détaché de ce qu'on appelle le présent qui, lui-même pourtant, devient passé au fur et à mesure qu'on entre dans l'avenir, à savoir à chaque instant. De là conçoit-on facilement l'histoire comme sécrétion de révolu. Pour "réoriginer " la culture française, il ne suffit pas de dire qu'il faut la recommencer " ailleurs et autrement ", faisant ainsi table rase de l'acquis et de l'hérité. C'est facile à dire, mais irréalisable dans la mesure où c'est quand même la culture française qui est recommencée et que le nouveau décollement ne peut pas être l'effet d'un délestage total. C'est précisément par ce qui se rassemble en nous du passé au titre d'une efficience de sens que nous avons suffisamment d'identité pour soumettre ce que nous sommes déjà à l'épreuve de l'altérité et ainsi changer nos mesures par le déplacement de nos limites, non par leur suppression.

Ces considérations conduisent tout droit à l'idée de création qui occupe une place centrale dans le texte. La création est présentée comme une exigence interne qu'on doit concilier avec 
l'idée d'une "pure force créatrice " ou " effort créateur " de l'individu, et qui a pour fonction d'apporter une solution toujours "aléatoire " à l'état d'aliénation intérieure dans lequel se trouve nécessairement l'indivu. Il fait plaisir de voir la créativité placée au cœur même de l'être de l'homme plutôt que présentée, ainsi que cela arrive souvent, comme une activité anodine capable de meubler agréablement le temps où l'homme se repose de ses périodes de sérieux. Mais cette créativité est bien celle de l'individu, et si cet individu a une identité qui résiste à l'évanouissement pur et simple et perpétuel dans l'autre, un peu à l'image et au rythme d'un temps dont le présent cède sans cesse à l'avenir pour devenir ce qu'il n'était pas, à savoir le passé, et si cette identité recueille en elle un fonds de réalité d'une densité telle que les mesures manqueront probablement toujours pour en déterminer le degré, on n'arrive pas facilement alors à comprendre comment cette créativité puisse apporter une solution " toujours aléatoire " à l'état d'aliénation intérieure de l'individu. S'agirait-il de créer encore à partir de rien? On comprendrait ainsi qu'il puisse sortir n'importe quoi de cette pure force créatrice. Mais si c'est toujours quelqu'un de bien déterminé qui crée, alors il paraît convenable d'atténuer la gratuité du résultat et d'imaginer un aléatoire tempéré par une certaine continuité de sens.

Est-ce du byzantinisme? Que non! Preuve: les conséquences. Une pure force créatrice, toute intérieure d'après le contexte, qui fournit des solutions aléatoires à un état d'aliénation également intérieur, ne peut, semble-t-il, que rester à à l'intérieur. On ne se trompe pas : "Or il n'est point d'autre solution à cet état d'aliénation, tout intérieur ne l'oublions pas, point d'autre solution que celle qui lui sera trouvée, toujours provisoirement, dans un autre monde, irréel et intérieur, à savoir celui-là même de la culture en tant qu'elle instaure un territoire imaginaire, irréductible à tout territoire réel. " Pour éviter, sans doute, l'absurdité d'une créativité humaine ex nibilo, dans le cas : aléatoire et tributaire de rien, on est obligé de maintenir le produit de cette création à l'intérieur de l'individu, et l'opposant ainsi à l'extérieur reconnu lui-même comme le réel, on lui confere le statut de l'imaginaire, c'est-à-dire de l'irréel. Et cela, c'est lè monde de la culture.

Pourquoi opposer l'imaginaire au réel ? Ne convient-il pas plutôt de le concevoir comme cette ouverture même que la réalité 
peut s'offrir chez l'homme et par lui pour se dépasser, c'est-à-dire effectuer une accession à l'altérité ? Et de la sorte l'imaginaire n'aurait rien d'irréel. Pourquoi, d'autre part, continuer à opposer l'intérieur à l'extérieur à la manière cartésienne, quand il s'agit de l'homme, comme s'il ne s'était rien dit depuis trois quarts de siècle sur l'hors-de-soi essentiel à toute intentionnalité de la conscience humaine ou à toute modalité d'existence? Peut-être parce que la culture est encore considérée bien abstraitement et pharisaïquement comme n'appartenant pas à la réalité quotidienne, et qu'alors il faut bien la confiner dans cet espace intérieur imaginaire et irréel. Il va de soi alors qu'il faille la dépayser puisqu'elle ne doit pas se souiller, comme pur signe de l'altérité, au contact des contours particuliers du territoire géographique. Il va de soi aussi que l'individu créateur doive être désidentifié au maximum parce que sa création culturelle ne serait pas pur dépassement, et qu'il n'aurait peut-être plus à supporter tout à fait solitairement l'angoisse de la déchirure existentielle.

Il semble cependant qu'on peut justement situer la culture dans le domaine de l'imaginaire ; ce serait le pays de la culture. Mais il apparaît que l'imaginaire, loin d'être confiné à l'intérieur de l'individu et réduit à l'irréel, doive être compris plutôt comme appartenant au réel même, lui permettant d'accéder à un plus être, d'être autrement qu'il ne serait sans lui ou d'apparaître selon une vérité plus intense. La métaphore de l'imaginaire investit tout le réel et signifie partout : de l'aménagement du territoire à la disposition du bâtiment et jusqu'à la représentation du jeu théâtral ou cultuel en passant par la présentation du tableau, celle du repas, du vêtement et du dire poétique. Comme imaginaire, la culture doit être omniprésente et doit tout représenter dans la claire manifestation de sa vérité. Cette manifestation n'est jamais une tâche achevée ; elle est toujours à reprendre et à perfectionner tant en intensité qu'en variété. Alors il ne faudrait pas dépayser ni départiculariser la culture. Au contraire, la poursuite jamais définitivement accomplie de son être-soi et de son être-vrai, en tant que ceux-ci impliquent essentiellement et toujours l'ouverture à l'altérité, l'essence même de la culture, peut bien exiger de passer par ces caractères distinctifs rattachés habituellement à l'habitation d'un pays et dont le premier en importance est sans contredit le langage.

Ainsi l'identité ou la distinction n'est pas nécessairement fixa- 
tion identitaire, ni coïncidence réflexive à un figé ou à un défini quelconque, ni reculade nostalgique au point d'origine de quelque cordon ombilical. Le nationalisme ou le dépaysement ne représentent pas un "ou bien ... ou bien ...." fermé et funeste.

Université du Québec à Montréal 